\section{Molekulargenetische Diagnostik der myotonen Dystrophie}

Hj. Müller am Morgen oft steif fühle und beim Velofahren zunehmend Schwierigkeiten habe, die Bremsen - vor allem, wenn es kalt ist - wieder loszulassen. Der Neurologe stellte ausser einer Schwäche des Musculus sternocleidomastoideus kaum weitere muskuläre Symptome fest. Das EMG zeigte aber die typischen myotonen Potentiale. Frau Meinherz leidet an einer milden Form der myotonen Dystrophie.

\section{Medizinisch-genetische Grundlagen}

Die myotone Dystrophie ist eine autosomal-dominant vererbte progressive Multisystemkrankheit. Man nimmt an, dass sie bei etwa 1 auf 8000 Einwohner unseres Landes vorkommt. Die verschiedenen Formen mit den Kardinalsymptomen sind in Tabelle 1 zusammengefasst. Während nur ganz ausnahmsweise ein leicht betroffener Vater mit einem schwer betroffenen Kind bekannt wurde, ist die oben geschilderte Antizipation bei Müttern nicht selten. Unter Antizipation versteht man die Tendenz einer Erbkrankheit, mit zunehmender Generation schwerer und früher aufzutreten.

\section{DNA-Diagnostik}

Die Molekulargenetik hat diese Zusammenhänge zwischen der angeborenen (Thomson), der klassischen (Curschmann-Steinert) und der milden Form geklärt. Das Gen auf dem Chromosom Nr. 19 kodiert eine Proteinkinase. Es enthält im terminalen $\mathrm{Ab}-$ schnitt, der keine Informationen mehr für die unmittelbare Zusammensetzung der Proteinkinase enthält, sogenannte "CTG- Repeats». Bei diesen "repeats» handelt es sich um aus 3 Nukleotiden zusammengesetzte

Korrespondenz:

Prof. Dr. med. Hansjakob Müller

Abteilung Medizinische Genetik UKBB

Departement Klinisch-Biologische Wissenschaften

CH-4005 Basel

Tabelle 1
Klinik der myotonen Dystrophie.

Klinik der myotonen Dystrophie und Anzahl der CTG- « repeats »

\begin{tabular}{|c|c|c|}
\hline Form & Klinische Symptome & Anzahl « repeats" \\
\hline \multirow[t]{2}{*}{ Mild } & - Katarakt & \multirow{2}{*}{$38-180^{*}$} \\
\hline & - diskrete myotonische Zeichen & \\
\hline \multirow[t]{5}{*}{ Klassisch } & - Myotonie & \multirow{5}{*}{$180-1000^{*}$} \\
\hline & - Muskelschwund & \\
\hline & - Stirnglatze & \\
\hline & - Hodenatrophie & \\
\hline & - Herzleitungsstörungen & \\
\hline \multirow[t]{3}{*}{ Kongenital } & - Hypotonie & \multirow{3}{*}{$>1000$} \\
\hline & - Mentale Retardierung & \\
\hline & - Faziale Dysphagie & \\
\hline
\end{tabular}

* Überlappungen 


\section{Abbildung 1}

Expansion bei myotropher Dystrophie.

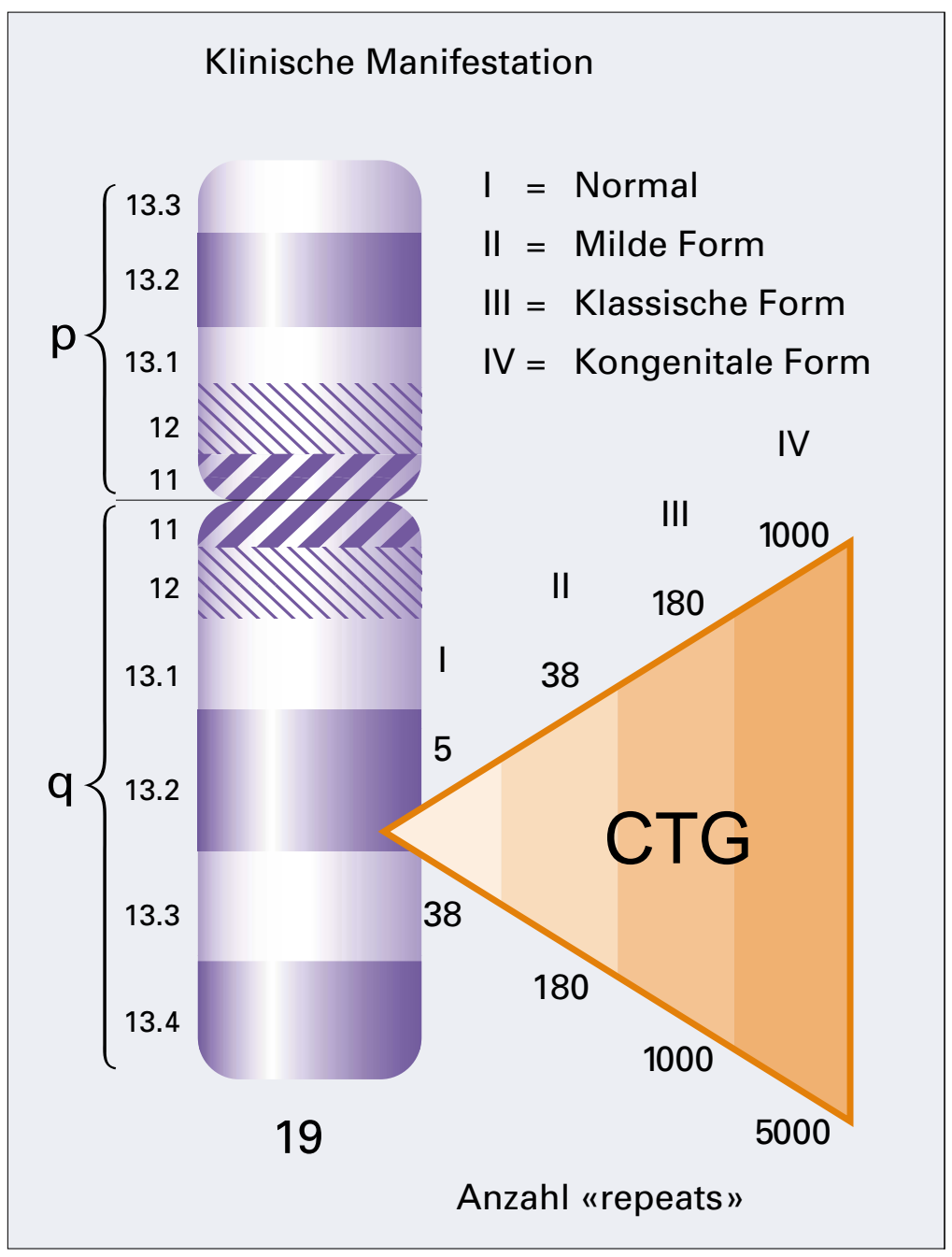

DNA-Motive, die in variabler Anzahl vorliegen können, wobei aber in der Regel diese Anzahl für einen bestimmten Genort konstant ist. Normalerweise hat man in beiden Genen nicht mehr als 37 "repeats». Ihre Zunahme auf einem Chromosom führt zu den beschriebenen Krankheitsbildern (Abb. 1). Dabei zeichnet sich eine Parallele zwischen dem Schweregrad der Krankheit und der Zahl der «repeats» ab: Bei der schwerkranken Tochter Ruth wurde bei der Gendiagnostik mittels "Southern-Blotting" auf einem Chromosom 19 eine enorme Vermehrung auf über 1500 «repeats» festgestellt, bei der Mutter Eva jedoch nur eine solche von 70. Deren Anzahl auf dem anderen Chromosom war bei Mutter und Tochter im Normbereich. Bei Frauen mit 50 und mehr "CTG- repeats" besteht die Gefahr, dass bei der DNA-Replikation der Zellen in der Keimbahn deren Zahl schlagartig zunehmen kann. Wird die davon betroffene Eizelle befruchtet, kommt ein schwerkrankes Kind zur Welt.

\section{Zur Bedeutung der DNA-Diagnostik}

Die Zahl der "repeats» wird in weissen Blutzellen bestimmt. Man benötigt dazu $10 \mathrm{ml}$ EDTA-Blut. Sie lässt sich auch an Chorionzotten oder gezüchteten Zellen aus dem Fruchtwasser erfassen. Frau Meinherz wünschte daher bei einer späteren Schwangerschaft eine pränatale Diagnose. Leider wurde beim Feten wiederum eine "repeat»-Zahl von über 1600 festgestellt. Frau Meinherz hat auch zwei Schwestern, die sich nun ebenfalls untersuchen lassen wollen, nachdem bei ihrem Vater in einem Chromosom eine "repeat"-Zahl von 60 festgestellt wurde. Bei ihm war als einziges Symptom ein Katarakt des posterioren Pols beider Linsen, der ihn nicht weiter gestört hat, festzustellen.

Neben der myotonen Dystrophie führen derartige Trinukleotid-«repeat»-Expansionen zum X-gonosomal vererbten Fragilen X-Syndrom (FRAX) oder zur autosomal-rezessiv vererbten Friedreichschen Ataxie. Bei der Chorea Huntington und bei weiteren neurodegenerativen Erkrankungen liegt eine Vermehrung von CAG-Trinukleotiden jeweils im kodierenden Abschnitt eines Gens vor.

\section{Was versteht man unter Southern-Blotting?}

Beim Southern-Blot handelt es sich um die älteste Methode zur Erfassung von Mutationen. Die DNA wird mit einem Restriktionsenzym in etwa 1 Million Fragmente zerschnitten. Diese werden elektrophoretisch nach ihrer Grösse aufgetrennt (Abb. 2). Im Nitrozellulose-Gel macht man sie einsträngig und führt eine radioktiv markierte DNA-Sonde (ebenfalls einsträngige DNA) hinzu, die sich nur an diejenigen Fragmente anlagern (mit ihnen hybridisieren) kann, die in ihrer Nukleotidzusammensetzung komplementäre Sequenzen enthalten. Dank der Sonde werden diese sichtbar gemacht. Ihre Grösse (Anzahl Nukleotide) kann mittels entsprechenden Markern bestimmt werden. Unterschiede in der Grössenordnung von Basenpaaren (bp), wie sie durch eine Zunahme der "repeats» enstehen können, respektive Mutationen, die die Schnittstelle des Restriktionsenzyms beeinflussen, können zuverlässig nachgewiesen werden. Für diese Form der DNA-Diagnostik werden $10 \mathrm{ml}$ EDTA-Blut, Chorionzotten oder gezüchtete Amnionzellen benötigt. 


\section{Abbildung 2}

Ablauf der DNA-Diagnostik mittels Southern-Blotting.

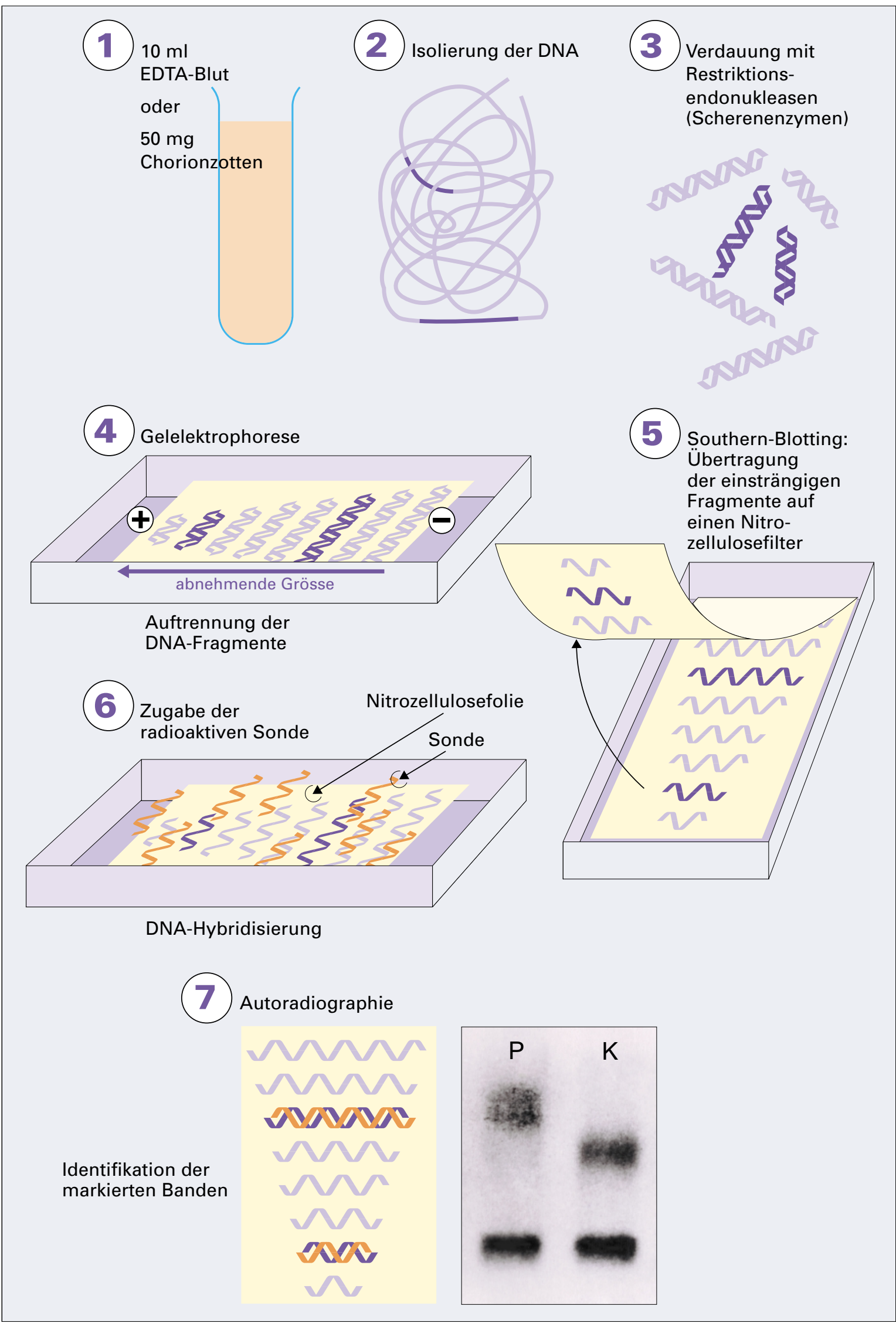

